\title{
Implementasi Sistem Informasi e-Document Pada Dinas Pekerjaan Umum Kota Semarang
}

\author{
Daniel Prasetyo Susanto \\ Program Studi S1 Sistem Informasi, Fakultas Teknologi Informasi, \\ Universitas Kristen Satya Wacana \\ Jalan Dr. O Notohamidjojo No. 1 - 10, Blotongan, Salatiga - 50711 \\ Email: 682016083@student.uksw.edu
}

\begin{abstract}
Abstrak-Penelitian ini bertujuan untuk mengimplementasi sistem informasi EDocument pada Dinas Pekerjaan Umum dengan merancang sebuah aplikasi. Dan menganalisa kekurangan-kekurangan sebagai penghambat kemajauan dari perusahaan Dinas Pekerjaan Umum dan melakukan pengujian pada suatu program dan menyelesaikan desain yang sudah disetujui. Hal ini dikarenakan strategi manajemen perusahaan Dinas Pekerjaan Umum dalam pengelolaan penyebaran dokumen masih manual dan pengambilan keputusan pada perusahaan dapat dipermudah. Dalam penelitian ini penulis melakukan studi kasus menggunakan metode EAP karena dianggap dapat menyelaaskan bisnis yang ada dan Teknologi yang sudah berjalan sebelumnya. Metode ini dapat mengidentifikasi mulai proses bisnis sampai ke perencanaan implementasi sitem informasi yang akan dibuat. Berdasarkan analisa mulai dari aktifitas utama sampai aktifitas pendukung maka diperoleh portofolio aplikasi sistem informasi pada Dinas Pekerjaan Umum Kota Semarang yang diantaranya adalah Sistem Informasi Pelayanan Publik, Sistem Informasi E-Document, Sistem Informasi Gudang, Sistem Informasi Keuangan, dan Sistem Informasi Kepegawaian, dimana dalam perencanaan aplikasi tersebut, hasil proses bisnis Dinas Pekerjaan Umum Kota Semarang dapat berjalan lebih efektif. Dengan Enterprise Architecture Planning (EAP) dapat dijadikan metode untuk mencapai sasaran bisnis Dinas Pekerjaan Umum Kota Semarang, selain itu keuntungan EAP adalah untuk mendukung pengambilan keputusan dan perencanaan yang baik. Walaupun penelitian dapat menghasilkan Sistem Infomasi yang mendukung cukup baik, namun masih perlu dilakukan peningkatan seperti upgrade Sistem oleh perusahaan agar dapat bersaing dengan manajemen perusahaan lain yang selalu mampu mengikuti kemajuan Teknologi.
\end{abstract}

Kata Kunci-Teknologi Informasi, Sistem Informasi, E-Document, EAP, Organisasi.

\section{PENDAHULUAN}

Perkembangan jaman dan juga teknologi yang semakin maju memudahkan segala pekerjaan manusia dalam mengerjakan suatu hal terutama di bidang administrasi. Sekarang sudah banyak dokumen yang sudah berkembang dalam manajemen berbasis digital. Sistem informasi diartikan sebagai kombinasi dari teknologi dan 
aktivitas orang-orang yang menggunakan tekonologi untuk mendukung operasi dan manajemen. Menurut James O'Brien (2010, p26) sistem adalah sekelompok komponen yang saling berhubungan, bekerja bersama untuk mencapai tujuan bersama dengan menerima input serta menghasilkan output dalam proses transformasi yang teratur. Seiring berkembangnya teknologi maka kebutuhan akan informasi yang cepat, tepat dan akurat sangat di butuhkan. Maka dari itu kebutuhan sistem informasi sudah menjadi kebutuhan mutlak diperusahaan Dinas Pekerjaan Umum.

Dinas Pekerjaan Umum Kota Semarang adalah Badan usaha milik negara yang bekerja dibidang pelayanan publik daerah Kota Semarang adapun tugasnya adalah melaksanakan urusan pemerintahan daerah di bidang pekerjaan umum, bidang penataan ruang dan bidang lingkungan hidup melalui perumusan kebijakan teknis, pembinaan, fasilitasi dan pelaksanaan kegiatan bina marga, sumber daya air, cipta karya, tata ruang dan tata perkotaan, air bersih, sanitasi dan drainase, pertamanan, persampahan serta pembinaan jasa konstruksi serta tugas lain yang diberikan oleh Walikota sesuai dengan perundang-undangan yang berlaku. Kondisi teknologi yang ada di dalam Dinas Pekerjaan Umum tersebut sebagian besar pengelolaan datanya masih bersifat manual, maka dari itu dibutuhkan suatu perencanaan strategis sistem informasi, yang tujuannya adalah proses bisnis di dalam perusahaan berjalan efektif.

Implementasi sistem dalam tahapan penerapan sistem yang akan dilakukan akan mengarah kepada sistem yang sudah disetujui termasuk program atau aplikasi yang sudah disiapkan pada tahap perencanaan sistem agar siap dioperasikan. Tujuan dari implementasi sistem informasi E-Document pada Dinas Pekerjaan Umum adalah merancang sebuah aplikasi dan menganalisa kekurangan-kekurangan sebagai penghambat kemajauan dari perusahaan Dinas Pekerjaan Umum dan melakukan pengujian pada suatu program dan menyelesaikan desain yang sudah disetujui. Manfaat implementasi pada perusahaan Dinas Pekerjaan Umum yaitu untuk mempermudah adanya pengelolaan penyebaran dokumen dimana akan mempermudah dalam pengambilan keputusan pada perusahaan. Mempermudah dalam pengunggahan, unduh, hapus dokumen atau data, cari dokumen, edit dokumen, memindahkan lokasi dokumen, mengupload sebuah dokumen yang telah diedit, mengurangi risiko kehilangan dokumen ataupun kerusakan dokumen, dan menyimpan berkas-berkas penting.

\section{STUDI PUSTAKA}

Implementasi Sistem Informasi E-Document sudah pernah ada dalam evaluasi Tata Kelola TI pada beberapa Perusahaan dan Instansi oleh berbagai peneliti terdahulu, oleh karena itu dalam penelitian ini akan diambil beberapa penelitian yang relevan untuk dijadikan sebagai acuan untuk menulis penilitan ini. Letsoin 
(2010), dalam penelitiannya mengkaji dokumen elektronik didalam hukum pembuktian di Indonesia, diakui esensinya setelah di atur di dalam UndangUndang Nomor 11 Tahun 2008 tentang Informasi dan Transaksi Elektronik bahwa informasi elektronik / dokumen elektronik dan/atau hasil cetaknya merupakan alat bukti hukum yang sah, dan merupakan perluasan dari alat bukti yang sah sesuai dengan hukum acara yang berlaku di Indonesia hal tersebut berdasarkan ketentuan pada Pasal 5 ayat 2 Undang-Undang Nomor 11 Tahun 2008.

Ardoni (2008), dalam penelitiannya menyimpulkan bahwa pada dasarnya pengelolaan dokumen elektronik tidak begitu berbeda dengan dokumen berbasis kertas. Meskipun demikian, terdapat beberapa pekerjaan lama yang tidak diperlukan dan beberapa pekerjaan baru yang perlu dilakukan. Senada dengan itu, sekurang-kurangnya ada lima aspek yang perlu diperhatikan dalam pengelolaan data elektronik, yakni: pembakuan format dan keamanan, pengindeksan dan pengabstrakan, penyediaan link ke sumber informasi lain, analisis akses dan sitiran, dan kesiapan pustakawan. Kurniawan (2008) dalam penelitiannya membahas tentang penerapan dokumen elektronik yang berbasis Digital Rights Managements (DRM) diharapkan melindungi informasi didalamnya terhadap orang-orang yang tidak mempunyai kepentingan. Tingkat kesuksesan penerapan dokumen berbasis DRM juga ditentukan kesiapan user.

\section{METODOLOGI}

Penelitian ini menggunakan pendekatakan kualitatif dengan jenis penelitian Nonrekayasa disampaikan oleh Istiyanto Jazi Eko, 2009 : Studi Kasus dimana studi kasus memiliki tujuan yang jelas terhadap bagaimana memahami objek yang diteliti dan secara khusus penelitian studi kasus tidak hanya untuk menjelaskan dan memahami objek yang diteliti saja tetapi menjelaskan bagaimana memberikan alasan mengapa masalah atau kasus tersebut layak untuk diteliti. Dengan adanya masalah atau kasus tersebut data yang dikumpulkan akan digunakan sebagai dasar dalam melakukan pengumpulan data.

Studi kasus dilakukan dengan objek Dinas Pekerjaan Umum Kota Semarang bagian kerja Sekertariat yang bertugas untuk melakukan pengelolaan dan penyusunan, diantaranya : penyebaran dokumen, bahan dokumentasi, data evaluasi laporan pelaksanaan program kerja, naskah dinas dan kearsipan serta program kerja dan anggaran. Kemudian dilakukan analisa data dengan mengacu kepada hasil data yang didapat dan memahami proses bisnis yang sedang berjalan di dalam instansi tersebut. Sehinggan nantinya didapat suatu sistem yang diperuntukan menjadi solusi dari studi kasus tersebut. 


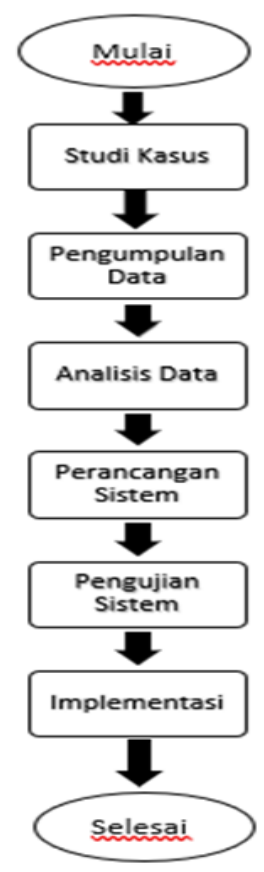

Gambar 1. Tahapan Penelitian

Studi kasus memiliki tujuan yang jelas terhadap bagaimana memahami objek yang diteliti dan secara khusus penelitian studi kasus tidak hanya untuk menjelaskan dan memahami objek yang diteliti saja tetapi menjelaskan bagaimana memberikan alasan mengapa masalah atau kasus tersebut layak untuk diteliti. Wawancara ini dilakukan dengan pimpinan pada seketariat Dinas Pekerjaan Umum kota Seamarang, bertujuan untuk memperoleh informasi yang dapat membantu penulis dalam mengelola masalah sehingga dapat dipakai untuk membangun suatu sistem yang diperuntukan menjadi solusi dari masalah tersebut. Kemudian analisa data dilakukan dengan mengacu kepada studi kasus yaitu hasil wawancara dan memahami proses bisnis yang sedang berjalan di dalam instansi tersebut.

Pada tahap selanjutnya atau perancangan sistem, dilakukannya langkah-langkah seperti permbuatan diagram Unified Modeling Language (UML) diantaranya : Use Case Diagram, Class Diagram, Activity Diagram dan rancangan antar muka atau User Interface. Tahapan dalam pembuatan system informasinya adalah pembuatan kode dengan perangkat lunak Visual Studio 2010, xampp v3.2.2 2015 sebagai control panel dan konfigurasinya, serta MySQL sebagai database dan penyimpanan data. Setelah itu dilakukan pengujian terhadap sistem yang telah dibangun tersebut dengan memasukan sistem tersebut ke dalam perangkat yang berbasis desktop untuk dioperasikan. 


\section{HASIL DAN PEMBAHASAN}

Pendekatan metodologi dimulai dari analisis kondisi bisnis dan SI/TI yang sudah berjalan namun dianggap kurang efektif, setelah itu menganalisis kondisi bisnis eksternal apakah pemanfaatan pemanfaatan SI/TI nya sudah maksimal. Terkadang SI/TI kurang dimanfaatkan karena lebih fokus kepada teknologinya itu sendiri, bukan melainkan berdasarkan kebutuhan bisnis organisasi. Dalam pembuatan sistem informasi tentu sebelumnya dilakukan pengelompokan data yang disebut Arsitektur Data. Arsitektur data dibuat untuk mengelompokkan data berdasarkan entitas data yang telah didefinisikan, entitas yang telah didefinisikan dapat digunakan untuk mendukung fungsi bisnis pada Dinas Pekerjaan Umum Kota Semarang, adapun daftar entitas data Dinas Pekerjaan Umum Kota Semarang sebagai berikut :

Tabel 1. Arsitektur Data

\begin{tabular}{|l|l|}
\hline \multicolumn{1}{|c|}{ Entititas Bisnis } & \multicolumn{1}{c|}{ Entititas Data } \\
\hline Entitas Pelayanan Informasi & 1.Entitas Pendaftaran \\
& 2.Entitas Informasi \\
& 3.Entitas Pengunjung \\
\hline Entitas Gudang & 1.Entitas Barang \\
& 2.Entitas Bon Barang \\
& 3.Entitas Laporan Barang masuk \\
& dan Keluar \\
& 4.Entitas Aset \\
\hline Entitas Surat dan Arsip & 1.Entitas Surat Masuk \\
& 2.Entitas Surat Keluar \\
& 3.Entitas Laporan Kegiatan \\
\hline Entitas Kepegawaian / SDM & 1.Entitas Pegawai \\
& 2.Entitas Gaji Pegawai \\
& 3.Entitas Kinerja Pegawai \\
\hline Entitas Pengelolaan Keuangan & 1.Entitas Anggaran \\
& 2.Entitas Laporan Kegiatan \\
& 3.Entitas Evaluasi Anggaran \\
\hline
\end{tabular}

Arsitektur Aplikasi dilakukan setelah pendefinisian entitas pada Arsitektur Data, mendefinisikan aplikasi yang dibutuhkan oleh perusahaan untuk mendukung proses bisnis dan pengelolaan database pada perusahaan tersebut. Arsitektur Aplikasi merupakan deskripsi tentang kemampuan dan manfaat dari aplikasi yang digunakan untuk mendukung proses bisnis (Trisminingsih, 2017). Arsitektur Aplikasi diperlihatkan pada tabel di bawah ini: 


p-ISSN: 2656-5935 http://journal-isi.org/index.php/isi e-ISSN: 2656-4882

Tabel 2. Arsitektur Aplikasi

\begin{tabular}{|c|c|c|c|}
\hline Aktivitas & Kebutuhan & Usulan SI/TI & Keterangan \\
\hline $\begin{array}{l}\text { Pelayanan } \\
\text { Informasi }\end{array}$ & $\begin{array}{l}\text { Membutuhkan } \\
\text { web profil untuk } \\
\text { memberi informasi } \\
\text { dan meningkatkan } \\
\text { pelayanan kepada } \\
\text { pengunjung }\end{array}$ & $\begin{array}{l}\text { Sistem informasi } \\
\text { pelayanan public }\end{array}$ & $\begin{array}{l}\text { Mengembangka } \\
\mathrm{n} \text { sistem yang } \\
\text { sudah ada }\end{array}$ \\
\hline $\begin{array}{l}\text { Pengunjung } \\
\text { gudang }\end{array}$ & $\begin{array}{l}\text { Membutuhkan } \\
\text { sistem informasi } \\
\text { untuk mengelola } \\
\text { asset dan barang } \\
\text { yang ada di } \\
\text { perusahaan }\end{array}$ & $\begin{array}{l}\text { Sistem informasi } \\
\text { gudang }\end{array}$ & $\begin{array}{l}\text { Pembuatan } \\
\text { sistem baru }\end{array}$ \\
\hline $\begin{array}{l}\text { Penyuratan } \\
\text { dan Arsip } \\
\text { SDM }\end{array}$ & $\begin{array}{l}\text { Membutuhkan } \\
\text { sistem untuk } \\
\text { mengelola/menyi } \\
\text { mpan surat dan } \\
\text { arsip laporan } \\
\text { Membutuhkan } \\
\text { sistem informasi } \\
\text { untuk mengelola }\end{array}$ & $\begin{array}{l}\text { Sistem informasi } \\
\text { e-document } \\
\text { Sistem informasi } \\
\text { kepegawaian }\end{array}$ & $\begin{array}{l}\text { Pembuatan } \\
\text { sistem baru } \\
\text { Mengembangka } \\
\text { n sistem yang } \\
\text { sudah ada }\end{array}$ \\
\hline $\begin{array}{l}\text { Pengelolaan } \\
\text { Keuangan }\end{array}$ & $\begin{array}{l}\text { data karyawan } \\
\text { Membutuhkan } \\
\text { aplikasi untuk } \\
\text { mengelola } \\
\text { keuangan, gaji } \\
\text { karyawan, dan } \\
\text { pembayaran }\end{array}$ & $\begin{array}{l}\text { Sistem informasi } \\
\text { keuangan }\end{array}$ & $\begin{array}{l}\text { Pembuatan } \\
\text { sistem baru }\end{array}$ \\
\hline
\end{tabular}

Analisis lingkungan SI/TI digunakan untuk melihat kondisi SI/TI pada kantor Dinas Pekerjaan Umum Kota Semarang dan terdapat beberapa aplikasi yang dimiliki oleh organisasi yang terlihat pada tabel di atas. Berdasarkan Tabel di atas usulan sistem informasi yang akan dibuat maupun dikembangkan antara lain: Sistem Informasi Pelayanan Publik, Sistem Informasi Gudang, Sistem Informasi E-Document, Sistem Informasi Kepegawaian, dan Sistem Informasi Keuangan. Implementasi Arsitektur Enterprise dibuat untuk perencanaan sistem informasi dan mengembangkan sistem informasi yang sudah ada atau sudah berjalan saat ini. Pengembangan aplikasi dilakukan karena sangat dibutuhkan untuk bebrapa tahun ke depan. Pengembangan aplikasi juga disesuaikan oleh kebutuhan dari organisasi. 
Setelah melakukan analisa dari beberapa tahapan dengan analisis terhadap sistem yang dimiliki oleh Dinas Pekerjaan Umum Kota Semarang maka tahapan usulan sistem informasi yang mampu menambah dan mendukung sistem yang telah ada agar tidak melakukan pekerjaan secara manual. Berikut ini merupakan gambaran aplikasi strategis yang dibutuhkan.

Tabel 3. Gambaran Aplikasi Strategis

\begin{tabular}{|l|l|}
\hline \multicolumn{1}{|c|}{ Strategi } & \multicolumn{1}{|c|}{ Aplikasi Berpotensi Tinggi } \\
\hline Sistem Informasi Gudang & Sistem Informasi Gudang \\
\hline Penyuratan Dan Arsip & Sistem Informasi E-Document \\
\hline $\begin{array}{l}\text { Sistem Informasi Sumber Daya } \\
\text { Manusia }\end{array}$ & Sistem Informasi Kepegawaian \\
\hline $\begin{array}{l}\text { Sistem Informasi Pengelolaan } \\
\text { Keuangan }\end{array}$ & Sistem Informasi Keuangan \\
\hline
\end{tabular}

Berdasarkan Tabel 3 di atas, aplikasi yang sedang direncanakan dan aplikasi yang akan dikembangkan membutuhkan waktu 5 tahun. Urutan perencanaan implemetasi aplikasi ini diurutkan berdasar fungsi dari aplikasi yang mendukung kegiatan bisnis Dinas Pekerjaan Umum Kota Semarang. Kondisi perkembangan teknologi saat ini Dinas Pekerjaan Umum Kota Semarang mulai menggunakan SI/TI berbasis web, desktop maupun mobile dalam proses bisnisnya untuk meningkatkan efektivitas dan efisiensi. Tujuannya untuk mengetahui strategi apa yang tepat dalam bersaing di tren penggunaan SI/TI pada Dinas Pekerjaan Umum Kota Semarang.

\section{KESIMPULAN}

Berdasarkan Studi kasus yang telah dilakukan di Dinas Pekerjaan Umum Kota Semarang bahwa denga memanfaatkan teknologi yang ada secara modern dan digunakan sesuai dengan prosedur, pengelolaan dilakukan dengan dua hal, yakni yang pertama dengan sistem manual dengan pencatatan tulis tangan pada setiap berkas. Untuk pencatatan surat dalam bentuk elektronik, menggunakan sistem digital memanfaatkan perangkat didalamnya, berkas-berkas surat yang sudah diproses tadi kemudian disimpan didalam komputer dan map agar lebih mudah dalam penemuan kembali bila nanti diperlukan lagi. Penerapan metode EAP merupakan strategi yang dapat digunakan untuk membantu menyelaraskan bisnis yang ada dan Teknologi yang sudah berjalan. Metode ini dapat mengidentifikasi mulai dari proses bisnis sampai ke perencanaan implementasi sistem informasi yang akan dibuat.

Berdasarkan analisa mulai dari aktifitas utama sampai aktifitas pendukung maka diperoleh portofolio aplikasi sistem informasi pada Dinas Pekerjaan Umum Kota Semarang yang diantaranya adalah Sistem Informasi Pelayanan Publik, Sistem 
Informasi E-Document, Sistem Informasi Gudang, Sistem Informasi Keuangan, dan Sistem Informasi Kepegawaian, dimana dalam perencanaan aplikasi tersebut hasil proses bisnis Dinas Pekerjaan Umum Kota Semarang dapat berjalan lebih efektif. Dengan Enterprise Architecture Planning (EAP) dapat dijadikan metode untuk mencapai sasaran bisnis Dinas Pekerjaan Umum Kota Semarang, selain itu keuntungan EAP adalah untuk mendukung pengambilan keputusan dan perencanaan yang baik.

\section{DAFTAR PUSTAKA}

[1] Barthos, Basri. 2013. Manajemen Kearsipan. Bumi Aksara. Jakarta

[2] Sugandha, Dann. 1991. Administrasi strategi, Taktik dan teknik penciptaan efisiensi. Jakarta : Intermedia.

[3] Istiyanto Jazi Eko, Widodo Aris Puji. 2009. Karakteristik Metodologi Penelitian Bidang Ilmu Komputer (IK) Berlandaskan Pendekatan Positivistik. Yogyakarta. Jurnal Sains dan Matematika.

[4] Anastasia Diana, Lilis Setiawati. 2011. Sistem Informasi Akuntansi, Perancangan, Prosedur dan Penerapan. Edisi 1. Yogyakarta: Andi Yogyakarta.

[5] Ningsih, Yanti Kurnia. 2004. Rancangan Sistem Informasi E-Dokumen dikantor Kecamatan Batu Ceper Kota Tangerang. Skripsi. Jurusan Sistem Informasi. Amalia, A. N. N., Afifuddin, A., \& Hayat, H. (2019).

[6] Amalia, A. N. N., Afifuddin, A., \& Hayat, H. (2019). IMPLEMENTASI EDOCUMENT DALAM PENGELOLAAN SURAT MASUK DAN KELUAR (Studi Kebijakan UU No. 11 Tahun 2008 Tentang Informasi dan Transaksi Elektronik di Bagian Umum Balai Kota Malang, Jawa Timur). Respon Publik, 13(3), 10-20.

[7] Kurniadi, Nobel. 2012. Membangun Sistem Informasi Kearsipan EDocument (Electronic Document).

[8] Yasin, Verdi. 2012. Rekayasa Perangkat Lunak Berorientasi Objek. Jakarta: Mitra Wacana Media.

[9] Nikpay, F., Ahmad, R. B., Rouhani, B. D., Mahrin, M. N., \& Shamshirband, S. (2017). An effective Enterprise Architecture Implementation Methodology, Information System and e-Business Management, 15(4), 927 962.

[10] Trisminingsih, R. (2017). Perancangan Arsitektur Enterprise untuk Koperasi pertanian menggunakan Enterprise Architecture Planning (Eap), Media Jurnal Informatika Vol. Periode Juli 2015, 7(01), 18-29.

[11] Sugandha, Dann. 1991. Administrasi strategi, Taktik dan Teknik penciptaan efisiensi. Jakarta : Intermed

[12] Pinem, D. B., MM, B. D., \& Erly Krisnanik, S. (2018). Implementasi Model Manajemen Kearsipan Desain Aplikasi E-Document Data Based Pada 
Kantor Kelurahan Pabuaran Mekar, Cibinong Bogor Jawa Barat. In Seminar Nasional Hasil Pengabdian Kepada Masyarakat (Vol. 1, No. 1).

[13] [12]. Solikin, I., \& Putra, M. S. (2018). Aplikasi E-document pada Kantor Kepala Desa Tugu Jaya Berbasis Website. Jurnal Cendikia, 16(2 Oktober), 89-94. 
243 | Implementasi Sistem Informasi e-Document Pada Dinas Pekerjaan ..... 